\title{
Genetic Stocks Used for Potato Genome Sequencing
}

\author{
Richard E. Veilleux
}

\begin{abstract}
Potato is a highly heterozygous and tetraploid crop and therefore it was a major challenge to decipher the potato genome. This chapter highlights the developmental stories of the potato genetic stock used for the whole genome sequencing by the Potato Genome Sequencing Consortium (PGSC).
\end{abstract}

\subsection{Introduction}

As difficulties arose with sequencing attempts on heterozygous potato germplasm, assembly of a draft sequence of the potato genome was contingent upon the utilization of a completely homozygous cultigen in this highly heterozygous tetraploid $(2 n=4 x=48)$ crop that declines rapidly on inbreeding. Cultivated potatoes all fall within Solanum tuberosum L. but have been divided taxonomically into indistinct Groups, including Group Tuberosum (tetraploid commercial cultivars grown throughout Europe and North America), and eight landrace populations grown in South America (Ajanhuiri Group, Andigenum Group, Chaucha Group, Chilotanum Group, Curtilobum Group, Juzepczukii Group,

R. E. Veilleux $(\bowtie)$

Department of Horticulture, Virginia Tech, Blacksburg, VA 24061, USA

e-mail: potato@vt.edu
Phureja Group, and Stenotomum Group) (Huáman and Spooner 2002). Ploidy was thought to distinguish the Groups: Ajanhuiri, Phureja and Stenotomum were diploid; Juzepczukii and Chaucha were triploid; Tuberosum, Andigenum and Chilotanum were tetraploid; Curtilobum was pentaploid. However, exceptions to the ploidy classification were common. The similarity between Groups Tuberosum and Andigenum have been demonstrated graphically in two independent studies where diverse populations of tetraploid Andigenum landraces have been bred to resemble commercial potato cultivars through recurrent selection (Glendinning 1975; Huarte and Plaisted 1984). Spooner et al. (2007) later used simple sequence repeat (SSR) markers to try to distinguish a collection of 742 landraces and reclassified the previous eight landrace Groups into four species, with two Groups [Andigenum (now including Andigenum, Phureja, Stenotomum and Chaucha) and Chlotanum] within $S$. tuberosum and Groups Ajanhuiri, Juzepczukii and Curtilobum elevated to species. The 
Andigenum Group then encompassed the genetically indistinct diploids, triploids and tetraploids whereas the other more genetically distinct Groups and species retained the ploidy status of their previous Groups. So, potato presents a wealth of germplasm from primitive cultivars to advanced tetraploid commercial clones with little difference genetically among them, justifying the use of a primitive cultivar to represent the potato genome. For the sake of clarity, we will continue to use the now extinct Group Phureja designation in this review.

There are only a few reports of inbreeding in tetraploid Group Tuberosum germplasm. Krantz (1946) reported an extensive study of inbreeding through self-pollination in five different families where the average tuber yield of subsequent generations declined from $83 \%$ of the original plant material in the $S_{1}$ generation to $19 \%$ in the $\mathrm{S}_{6}$ generation. The data for the $\mathrm{S}_{6}$ generation were limited to only one of the five starting families due to a high proportion of weak plants that failed to flower in other families. The rapid decline of tetraploid potatoes after even a single generation of inbreeding has been confirmed in a wide range of germplasm, especially if starting with the most productive cultivars (Golmirzaie et al. 1998a, b; Hagberg and Tedin 1951). Many studies have been conducted on potato dihaploids, i.e., derivatives of tetraploid selections with the diploid chromosome number ( $2 n=2 x=24)$ obtained by prickle pollination (Uijtewaal et al. 1987a) or anther culture (Wenzel et al. 1979). Most dihaploids exhibit reduced vigor compared to the tetraploid progenitors, averaging only $50 \%$ of the yield and most do not shed functional pollen (Rokka 2009), limiting their utility in breeding. In an extensive study of 5377 dihaploids extracted from 31 different tetraploid clones, Hutten et al. (1995) found that $39 \%$ of a subset of the most vigorous did not tuberize and $32 \%$ did not flower. Although dihaploids have reduced heterozygosity compared to tetraploid cultivars, they still exhibit considerable heterozygosity and are therefore unsuitable nominees for sequencing as the differences in intergenic DNA on homologous chromosomes defied assembly using the sequencing platforms available in 2011. Reduction of dihaploids to the monoploid level $(2 n=1 x=12)$ requires functional female gametes using prickle pollination or functional male gametes using anther culture, assuming that the genetic load were sufficiently light to obtain a viable monoploid genome. Uijtewaal et al. (1987b) obtained true monoploids (synonymous with monohaploids) from two different dihaploid families by prickle pollination; after chromosome doubling, these are the only reported truly homozygous plants obtained primarily from Solanum tuberosum Group Tuberosum germplasm. Yet, even in this case, a close look at the parental material reveals that Group Phureja diploids comprised either 3/8 (M9 family) or $1 / 2$ (H78.01 family) of their composition (De Vries et al. 1987; Uijtewaal et al. 1987b). The monoploids and doubled monoploids obtained were extremely weak with little or no tuber set (Uijtewaal et al. 1987b). Because of the heavy genetic load of tetraploid Group Tuberosum germplasm revealed in these studies of chromosome reduction, it was an unlikely source of a suitable homozygous clone for sequencing. In any case this source of plant material was no longer available at the time when sequencing was first seriously envisioned.

Due to the lack of availability of a homozygous line derived from tetraploid Tuberosum germplasm, an alternative source of homozygous potato lines was necessary. Diploid accessions of Group Andigenum germplasm would be expected to carry a less crippling genetic load than tetraploids as they would have been subjected to more purifying selection through sexual propagation as well as reduced masking of deleterious alleles at the diploid compared to the tetraploid level. In order to demonstrate the possibility of homozygous potato germplasm, we embarked on a program starting in the 1980 s to extract monoploids from diploid Phureja germplasm (Fig. 4.1). Our starting material was sexually propagated derivatives of the Phureja population bred for photoperiod adaptation to long days in North Carolina (Haynes 1972). We screened selected seedlings randomly from crosses among diplandrous ( $2 n$ pollen-producing) clones within 
Fig. 4.1 Tubers of a diverse population of adapted Phureja

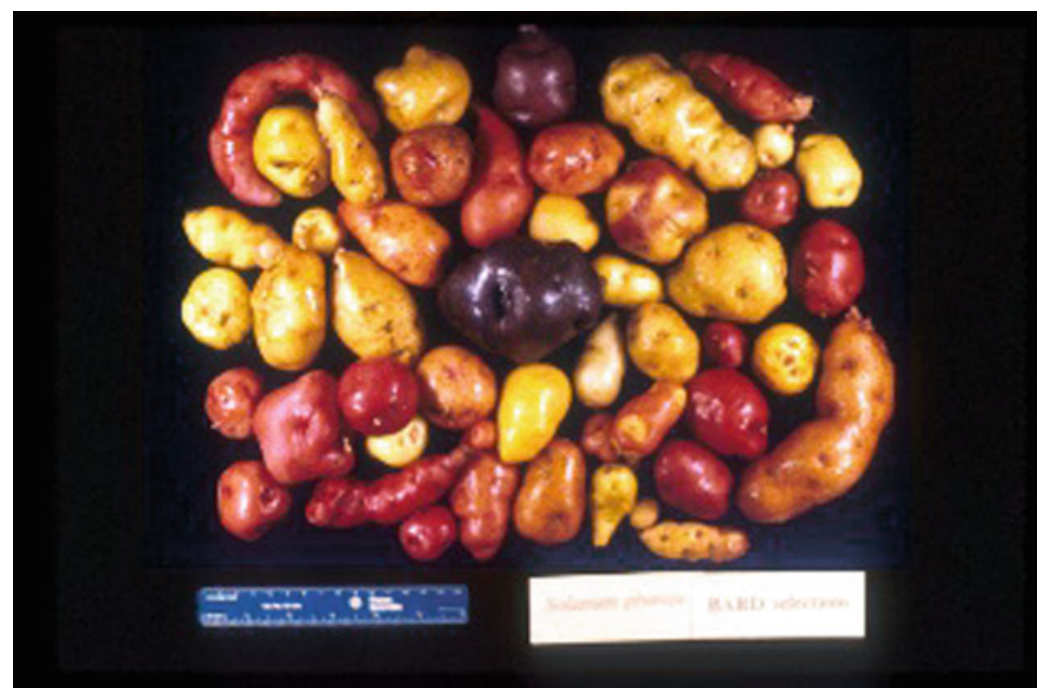

Fig. 4.2 Anther-derived embryos of diploid potato

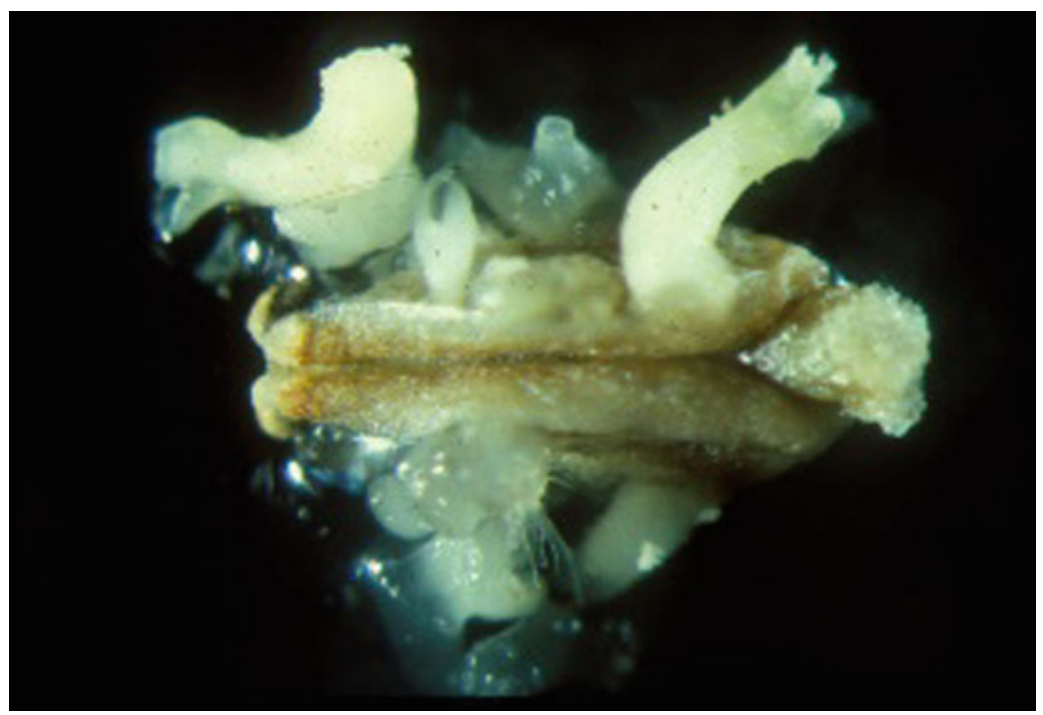

a diverse population (Veilleux and Lauer 1981) for their ability to form embryos in anther culture (Fig. 4.2) using the protocol described by Wenzel et al. (1979). The rationale of using diplandrous clones was to derive monoploid plants from reduced pollen grains while retaining the ability of the resulting monoploids or their sexually derived hybrids to generate $2 n$ pollen through fused or parallel spindles at the second division of microsporogenesis, thereby providing building blocks for sexual polyploidization in future applications. The corollary, however, was that the embryos generated from heterozygous $2 n$ microspores in anther culture would be more vigorous and outcompete the relatively weak sought-after monoploid embryos from $1 n$ microspores. Another complication was that diploids derived by anther culture would include heterozygous $2 n$ pollen-derived clones as well as homozygous clones from spontaneously doubled $1 n$ embryos or even $2 n$ plants from somatic anther tissue. All diploids were routinely discarded as the effort of sorting homozygous from heterozygous clones using whatever marker 
Fig. 4.3 Monoploid and isogenic doubled monoploid potato

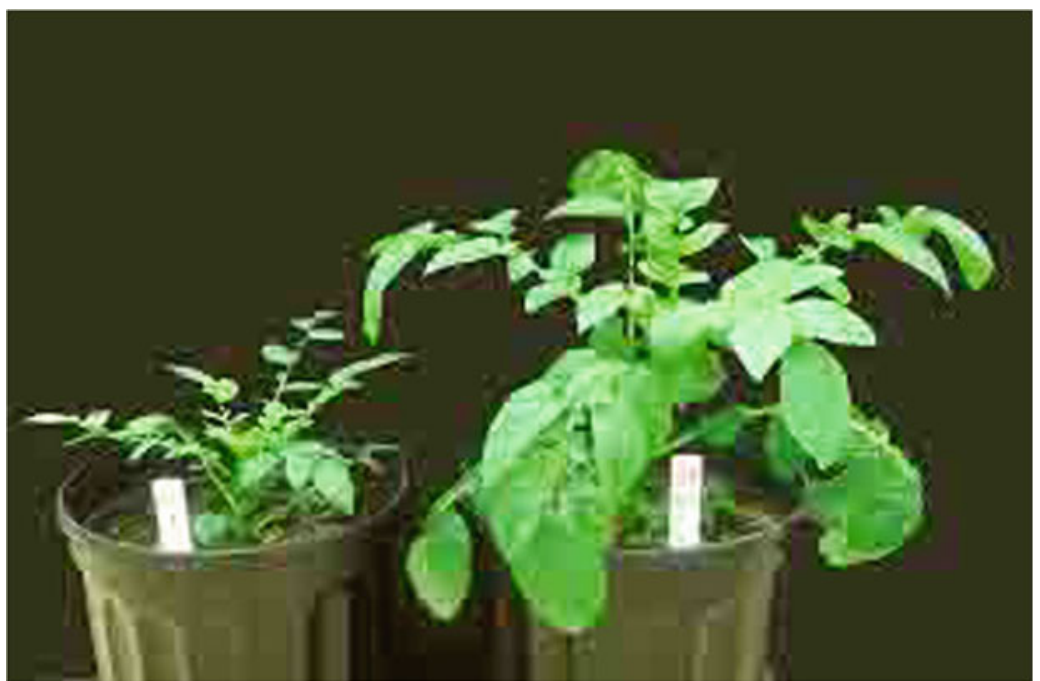

system was in vogue at the time was deemed too great (Veilleux et al. 1995). Instead, verified monoploids were subjected to a leaf disc regeneration protocol (Hulme et al. 1992) resulting in diploidization (Fig. 4.3) either through regeneration from pre-existing endoreduplication in leaf explants or spontaneous endoreduplication during regeneration from callus (Paz and Veilleux 1999).

The first set of anther-derived embryos and plants derived from the adapted Phureja population was recovered from a single seedling that responded positively to anther culture (Veilleux et al. 1985). The homozygous plants, though weak compared to their heterozygous diploid anther donor, were sufficiently viable for greenhouse trials, field trials (Lough et al. 2001) and, once doubled (Fig. 4.3), crosses as stylar parents to various heterozygous pollinator plants (M'Ribu and Veilleux 1992). A modest effort was made to enlarge the germplasm base by screening for other anther culture-competent selections within the adapted Phureja seedling population to generate a more genetically diverse homozygous Phureja germplasm base (Johnson et al. 2001). Over the years, various efforts were made to improve the vigor of Phureja monoploids through somatic hybridization (Haynes 1972; Johnson et al. 2001; Lightbourn and Veilleux 2007) and outcrossing followed by re-extraction of monoploids (M'Ribu and Veilleux 1992; Paz and Veilleux 1997). The monoploids and doubled monoploids were maintained in vitro for many years at Virginia Tech and some were deposited in the Potato Gene Bank (http://www.ars-grin. gov/nr6/; most easily found by searching for germplasm developed by Veilleux) or provided to the International Potato Center (accession CIP 801092). One of the heterozygous anther donor clones, BARD 1-3, is also maintained at the US Potato Gene Bank as accession GS 224. As the response to anther culture was found to be a highly hereditable trait (Taylor and Veilleux 1992), seedling families obtained from crosses between anther-derived doubled monoploids and a range of heterozygous pollinators can be expected to respond to anther culture. Such seedling families have been generated at CIP, Virginia Tech and elsewhere. Likewise, tetraploid somatic hybrids derived by intermonoploid protoplast fusions (Lightbourn and Veilleux 2007) also respond positively to anther culture and represent heterozygous potato germplasm where all alleles would have passed through the monoploid sieve (Wenzel et al. 1979). One of these somatic hybrids is maintained by the US Potato Gene Bank as accession GS 220 (https:// npgsweb.ars-grin.gov/gringlobal/accessiondetail. aspx?id=1648798). Hence, a limited variety of homozygous potato germplasm has been made 
Fig. 4.4 Tubers of DM BARD 1-3 516 R44

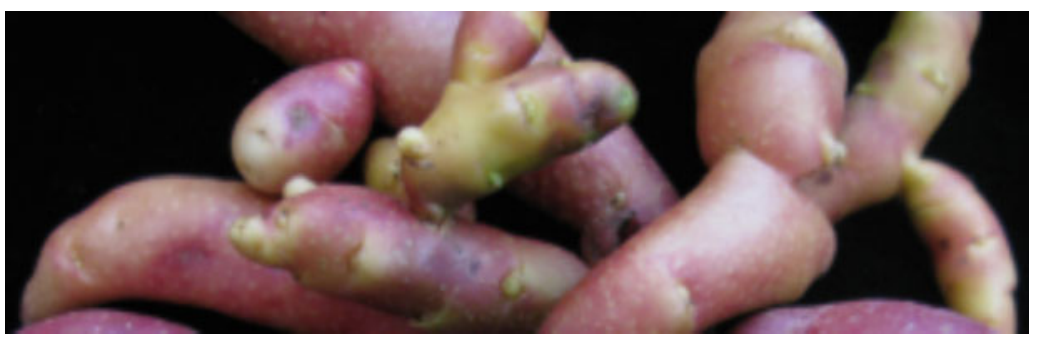

available in recent years; most generated through haploid extraction with the aim of facilitating genetic studies rather than direct breeding applications.

When the Potato Genome Sequencing Consortium (PGSC) became frustrated with attempts to assemble the sequence of the heterozygous dihaploid potato clone, RH89-039-16, a search for homozygous potato germplasm that might be more amenable to sequencing using available Sanger, Roche 454 Pyrosequencing and Illumina Sequencing by Synthesis platforms was initiated. DM BARD 1-3 516 R44 (DM) was available at both Virginia Tech and CIP, facilitating its distribution to partner institutions in the PGSC. It had been extracted as one of many monoploids from heterozygous adapted Phureja clone BARD 1-3, then subjected to chromosome doubling by leaf disc regeneration (Paz and Veilleux 1999). The designation R44 is simply the 44th shoot regenerated that was later identified as a diploid. As with most selections of Phureja, DM prefers a cool season $\left(22{ }^{\circ} \mathrm{C}\right.$ days $/ 16{ }^{\circ} \mathrm{C}$ nights); under these conditions, it will grow slowly but, once established, will flower (white flowers) and set fruit when pollinated by a fertile diploid potato selection. Although it produces stainable pollen, there are no reports of pollen fertility. It tuberizes after a few weeks, sooner if grown under a short $12 \mathrm{~h}$ photoperiod, later if grown under a long $16 \mathrm{~h}$ photoperiod. The tubers (Fig. 4.4) are fingerling, yellow fleshed, slightly and variably red-skinned and have poor keeping quality as they often exhibit tuber end rot even when still attached to the mother plant. Because of its homozygosity in intergenic as well as genic regions of the genome, the DM genome sequence was assembled rapidly and published in 2011 (The Potato Genome
Sequencing Consortium 2011) where $86 \%$ of the $844 \mathrm{Mb}$ genome was assembled and some 39,000 genes predicted. The genome assembly was later improved through marker analysis of a backcross population of DD $x$ (DM x DD) where DD was a heterozygous clone of $S$. tuberosum Group Andigenum Goniocalyx cultivar group (Sharma et al. 2013).

\subsection{Conclusion}

As of March, 2017, the original publication of the DM sequence has been cited more than 500 times, providing a framework for studies of gene families (Charfeddine et al. 2015; Gao et al. 2016; Ma et al. 2016; Schreiber et al. 2014; Seo et al. 2016; Tang et al. 2016; Van Harsselaar et al. 2017), a scaffold for alignment of transcriptomic data (Campbell et al. 2014; Gong et al. 2015; Goyer et al. 2015; Liu et al. 2015; Morris et al. 2014; Tang et al. 2014) or a reference genome against which to discover genomic variation (Hardigan et al. 2016), to cite just a few. As sequencing platforms improve, the DM assembly will likely be supplanted by that of a more robust commercial potato line. In the meantime, it will have served its purpose to bring this genetically clumsy, yet important, crop into the genomic era.

\section{References}

Campbell R, Pont SDA, Morris JA, McKenzie G, Sharma SK, Hedley PE, Ramsay G, Bryan GJ, Taylor MA (2014) Genome-wide QTL and bulked transcriptomic analysis reveals new candidate genes for the control of tuber carotenoid content in potato 
(Solanum tuberosum L.). Theor Appl Genet 127 (9):1917-1933

Charfeddine S, Saidi MN, Charfeddine M, Gargouri-Bouzid R (2015) Genome-wide identification and expression profiling of the late embryogenesis abundant genes in potato with emphasis on dehydrins. Mol Biol Rep 42:1163-1174

De Vries SE, Ferwerda MA, Loonen A, Pijnacker LP, Feenstra WJ (1987) Chromosomes in somatic hybrids between Nicotiana plumbaginifolia and a monoploid potato. Theor Appl Genet 75(1):170-176

Gao JP, Cao XL, Shi SD, Ma YL, Wang K, Liu SJ, Chen D, Chen Q, Ma HL (2016) Genome-wide survey of Aux/IAA gene family members in potato (Solanum tuberosum): Identification, expression analysis, and evaluation of their roles in tuber development. Biochem Biophys Res Commun 471(2):320-327

Glendinning DR (1975) Neo-tuberosum: new potato breeding material. 2. A comparison of neo-tuberosum with unselected Andigena and with Tuberosum. Potato Res 18(3):343-350

Golmirzaie AM, Bretschneider K, Ortiz R (1998a) Inbreeding and true seed in tetrasomic potato. II. Selfing and sib-mating in heterogeneous hybrid populations of Solanum tuberosum. Theor Appl Genet 97 (7):1129-1132

Golmirzaie AM, Ortiz R, Atlin GN, Iwanaga M (1998b) Inbreeding and true seed in tetrasomic potato. I. Selfing and open pollination in Andean landraces (Solanum tuberosum Gp. Andigena). Theor Appl Genet 97 (7):1125-1128

Gong L, Zhang HX, Gan XY, Zhang L, Chen YC, Nie FJ, Shi L, Li M, Guo ZQ, Zhang GH, Song YX (2015) Transcriptome profiling of the potato (Solanum tuberosum L.) plant under drought stress and water-stimulus conditions. PLoS ONE 10(5): e0128041

Goyer A, Hamlin L, Crosslin JM, Buchanan A, Chang JH (2015) RNA-seq analysis of resistant and susceptible potato varieties during the early stages of potato virus Y infection. BMC Genom 16:472

Hagberg A, Tedin O (1951) Inter- and intraclonal crosses and inbreeding in potatoes. Hereditas 37(1-2):280287

Hardigan MA, Crisovan E, Hamilton JP, Kim J, Laimbeer P, Leisner CP, Manrique-Carpintero NC, Newton L, Pham GM, Vaillancourt B, Yang XM, Zeng ZX, Douches DS, Jiang JM, Veilleux RE, Buell CR (2016) Genome reduction uncovers a large dispensable genome and adaptive role for copy number variation in asexually propagated Solanum tuberosum. Plant Cell 28(2):388-405

Haynes FL (1972) The use of cultivated diploid Solanum species in potato breeding. In: French ER (ed) Prospects for the potato in the developing world: an international symposium on key problems and potentials for greater use of the potato in the developing world, Lima, Peru. International Potato Center (CIP), pp 100-110
Huáman Z, Spooner DM (2002) Reclassification of landrace populations of cultivated potatoes (Solanum sect. Petota). Am J Bot 89(6):947-965

Huarte MA, Plaisted RL (1984) Selection for tuberosum likeness in the vines and in the tubers in a population of Neotuberosum. Am Potato J 61(8):461-473

Hulme JS, Higgins ES, Shields R (1992) An efficient genotype-independent method for regeneration of potato plants from leaf tissue. Plant Cell Tiss Org Cult 31(2):161-167

Hutten RCB, Soppe WJJ, Hermsen JGT, Jacobsen E (1995) Evaluation of dihaploid populations from potato varieties and breeding lines. Potato Res 38(1):77-86

Johnson AAT, Piovano SM, Ravichandran V, Veilleux RE (2001) Selection of monoploids for protoplast fusion and generation of intermonoploid somatic hybrids of potato. Am J Potato Res 78(1):19-29

Krantz EA (1946) Potato breeding methods. III. A suggested procedure for potato breeding. Bulletin of Minnesota Agricultural Experimental Station No. 173

Lightbourn GJ, Veilleux RE (2007) Production and evaluation of somatic hybrids derived from monoploid potato. Am J Potato Res 84(5):425-435

Liu BL, Zhang N, Wen YK, Jin X, Yang JW, Si HJ, Wang D (2015) Transcriptomic changes during tuber dormancy release process revealed by RNA sequencing in potato. J Biotechnol 198:17-30

Lough RC, Varrieur JM, Veilleux RE (2001) Selection inherent in monoploid derivation mechanisms for potato. Theor Appl Genet 103(1):178-184

M'Ribu HK, Veilleux R (1992) Fertility of doubled monoploids of Solanum phureja. Am Potato J 69 (7):447-459

Ma HL, Cao XL, Shi SD, Li SL, Gao JP, Ma YL, Zhao Q, Chen Q (2016) Genome-wide survey and expression analysis of the amino acid transporter superfamily in potato (Solanum tuberosum L.). Plant Physiol Biochem 107:164-177

Morris WL, Hancock RD, Ducreux LJM, Morris JA, Usman M, Verrall SR, Sharma SK, Bryan G, McNicol JW, Hedley PE, Taylor MA (2014) Day length dependent restructuring of the leaf transcriptome and metabolome in potato genotypes with contrasting tuberization phenotypes. Plant Cell Environ 37(6):1351-1363

Paz MM, Veilleux RE (1997) Genetic diversity based on randomly amplified polymorphic DNA (RAPD) and its relationship with the performance of diploid potato hybrids. J Am Soc Hort Sci 122(6):740-747

Paz MM, Veilleux RE (1999) Influence of culture medium and in vitro conditions on shoot regeneration in Solanum phureja monoploids and fertility of regenerated doubled monoploids. Plant Breed 118(1):53-57

Rokka VM (2009) Potato Haploids and Breeding. In: Touraev A, Forster BP, Jain SM (eds) Advances in haploid production in higher plants. Springer, New York, pp 199-208

Schreiber L, Nader-Nieto AC, Schonhals EM, Walkemeier B, Gebhardt C (2014) SNPs in genes functional in starch-sugar interconversion associate with natural 
variation of tuber starch and sugar content of potato (Solanum tuberosum L.). G3: genes|genomes |. Genetics 4(10):1797-1811

Seo E, Kim S, Yeom SI, Choi D (2016) Genome-wide comparative analyses reveal the dynamic evolution of nucleotide-binding leucine-rich repeat gene family among Solanaceae plants. Front Plant Sci 7:1205

Sharma SK, Bolser D, de Boer J, Sønderkær M, Amoros W, Carboni MF, D'Ambrosio JM, de la Cruz G, Di Genova A et al (2013) Construction of reference chromosome-scale pseudomolecules for potato: integrating the potato genome with genetic and physical maps. G3: Genes|Genomes|Genetics 3:2031-2047

Spooner DM, Núñez J, Trujillo G, Herrera MD, Guzmán F, Ghislain M (2007) Extensive simple sequence repeat genotyping of potato landraces supports a major reevaluation of their gene pool structure and classification. Proc Nat Acad Sci USA 104(49):19398-19403

Tang X, Datema E, Guzman MO, de Boer JM, van Eck HJ, Bachem CWB, Visser RGF, de Jong H (2014) Chromosomal organizations of major repeat families on potato (Solanum tuberosum) and further exploring in its sequenced genome. Mol Genet Genomics 289 (6):1307-1319

Tang RM, Zhu WJ, Song XY, Lin XZ, Cai JH, Wang M, Yang Q (2016) Genome-wide identification and function analyses of heat shock transcription factors in potato. Front Plant Sci 7:490

Taylor TE, Veilleux RE (1992) Inheritance of competences for leaf disk regeneration, anther culture, and protoplast culture In Solanum phureja and correlations among them. Plant Cell Tiss Org Cult 31(2):95-103
The Potato Genome Sequencing Consortium (2011) Genome sequence and analysis of the tuber crop potato. Nature 475(7355):189-195

Uijtewaal BA, Huigen DJ, Hermsen JG (1987a) Production of potato monohaploids $(2 n=x=12)$ through prickle pollination. Theor Appl Genet 73(5):751-758

Uijtewaal BA, Jacobsen E, Hermsen JGT (1987b) Morphology and vigor of monohaploid potato clones, their corresponding homozygous diploids and tetraploids and their heterozygous diploid parent. Euphytica 36 (3):745-753

Van Harsselaar JK, Lorenz J, Senning M, Sonnewald U, Sonnewald S (2017) Genome-wide analysis of starch metabolism genes in potato (Solanum tuberosum L.). BMC Genomics 18

Veilleux RE, Booze-Daniels J, Pehu E (1985) Anther culture of a $2 n$ pollen producing clone of Solanum phureja Juz. and Buk. Can J Genet Cytol 27(5):559_ 564

Veilleux RE, Lauer FI (1981) Breeding behavior of yield components and hollow heart in tetraploid-diploid vs conventionally derived potato hybrids. Euphytica 30 (3):547-561

Veilleux RE, Shen LY, Paz MM (1995) Analysis of the genetic composition of anther-derived potato by randomly amplified polymorphic DNA and simple sequence repeats. Genome 38(6):1153-1162

Wenzel G, Schieder O, Przewozny T, Sopory SK, Melchers G (1979) Comparison of single cell-culture derived Solanum tuberosum L. plants and a model for their application in breeding programs. Theor Appl Genet 55(2):49-55 